\title{
SEMÂNTICA SOCIAL E ETNOMÉTODOS: Metodologia da Pesquisa do Senso Forense da Decisão Jurídica'
}

\author{
SOCIAL SEMANTICS AND ETNOMETHODS: Methodology of Rescarch of Forensic Sense of Legal \\ Decision
}

\author{
Artur Stamford ${ }^{\circ}$
}

\begin{abstract}
Resumo:
Pesquisar a decisão juridica requer mais que estudar a teoria da interpretação e a teoria da argumentação, envolve o estudo da vida cotidiana da comunidade forense. É que as decisões não são mera aplicação das normas jurídicas, nem da racionalidade argumentativa, elas são fruto de processos comunicativos desenvolvidos na comunidade forense. Para tratar do tema relacionamos a visão semântica de Niklas Luhmann com a etnometodologia de Harold Garfinkel, o que nos proporciona uma explicação sociológica da construção do Direito a partir da comunidade forense adicionada à identificação de etnométodos forenses.
\end{abstract}

Palavras-chave: Norma jurídica. Processos comunicativos. Etnometodologia.

\begin{abstract}
:
To research the juridical decision requests more than to study the theory of the interpretation and the theory of the argument, it involve the study of the juridical community's daily life. The decisions are not mere application of the rules of law, nor of the argumentative rationality, they are fruit of communicative processes developed in the juridical community. To treat of the theme we related Niklas Luhmann's semantic vision with Harold Garfinkel's ethnomethodology, what provides us a sociological explanation of the construction of the right starting from the juridical community added to the identification of juridical ethnomethods.
\end{abstract}

Keywords: Rules of Law. Communicative processes. Ethnomethodology.

1. Introdução

Se a redução do direito ao Estado já foi um paradigma na Ciência do Direito, na literatura jurídica atual não se verifica essa visão do direito. Autores dedicados à visão dogmática já não fazem essa redução do fenômeno social juridico.'

O Autor é convidado do Professor Associado ao Departamento de Filosofia e Teoria Geral do Direito, Eduardo Carlos Bianca Bittar, com decisão favorável da Comissão de Publicação desta Revista, reunida em outubro de 2006.

- Doutor em Teoria, Fílosofia e Sociologia do Direito pela Universidade Federal de Pemambuco. Professor Adjunto da Universidade Federal de Pernambuco.

1 Como exemplos citamos: Ricardo Lobo Torres. Normas de interpretação e integração do direito Iributário. Rio de Janeiro/São Paulo: Renovar, 2000; Luiz Edson Fachin. Repensando fundamentos do direilo civil brasileiro contemporâneo. Rio de Janeiro/São Paulo: Renovar. 2000; CARVALHO. Paulo de Barros. Teoria da norma tributária. Rio de Janeiro: Max Limonad, 2002; LOBO, Paulo Luiz Netto. 
Não por isso se pode comemorar uma mudança no paradigma jurídico. Ampliar o direito à sociedade, todavia, requer a construção de uma metodologia adequada e capaz de enfrentar as temáticas e problematizações impostas por essa ampliação.

Quando o objeto de pesquisa é a decisão jurídica e o seu objetivo é propor uma explicação à pluralidade de decisões nos tribunais é inevitável a não-redução do direito ao texto da norma estatal, por mais significado que se pretenda ao signo norma jurídica.

Antes de tratar do tema, uma advertência. Estou convencido que quando Thomas Khun escreveu que os manuais, "livros que se tornaram populares no século XIX, revelam os paradigmas compartilhados pela comunidade cientifica" e, portanto, possibilitam a evolução da ciència normal - aquela baseada em realizações científicas passadas - por que manuais expõem o corpo da teoria aceita para as gerações futuras (2000, p. 29; 40;67-71), ele não conhecia os manuais de Direito.

Se houve época em que a doutrina serviu para auxiliar as decisões judiciais, atualmente é questionável essa função da doutrina jurídica. principalmente os manuais que não fazem mais que reproduzir o texto legislativo, quando não aguardam as decisões dos tribunais para, enfïm, lançar seus livros. Quem sabe por isso o ministro Humberto Gomes de Bartos, do STJ, em seu voto n. AgReg em FRESP n. 279.889-AL, declarou que:

Não me importa o que pensam os doutrinadores. Enquanto for ministro do Superior Tribunal de Justiça, assumo a autoridade da minha jurisdição. O pensamento daqueles que não são ministros deste Tribunal importa como orientação. A eles, porém, não me submeto. Interessa conhecer a doutrina de Barbosa Moreira ou Athos Carneiro. Decido, porém, conforme minha consciência. Precisamos estabelecer nossa autonomia intelectual, para que este Tribunal seja respeitado. É preciso consolidar o entendimento de que os senhores ministros Francisco Peçanha Martins e Humberto Gomes de Barros decidem assim, porque pensam assim. E o STJ decide assim, porque a maioria de seus integrantes pensa como esses Ministros. Fsse é o pensamento do Superior Tribunal de Justiça, e a doutrina que se amolde a ele. É fundamental expressarmos o que somos. Ningućm nos dá lições. Não somos aprendizes de ninguém. Quando viemos para este Tribunal, corajosamente assumimos a declaração de que temos notável saber jurídico uma imposição da Constituição Federal. Pode não ser verdade. Em relação a mim,

Direito civil comentado. São Paulo: Atlas, 2003; TEPEDINO, Gustavo; MURAl:S. Maria C. Bodin de: BARBOZA, Heloias Helena. Código civil interprelado conforme a constituiçăo. Rio de Janeiro: Renoar. 2004; ROCHA, José Albuquerque. Teoria geral do processo. São Paulo: Allas, 2005; DINAMARCO. Candido Rangel. Instrumentalidade do processo. São Paulo: Malheiros. 2005. 
certamente, não é, mas, para efeitos constitucionais, minha investidura obriga-me a pensar que assim seja.

Se a doutrina a que o ministro se refere é a dos manuais reprodutores de texto legislado e de uma coleção de ementas de decisões dos tribunais, não há como discordar dessa opinião. Por outro lado, se a referência é aos doutrinadores cientistas do direito, sua opinião apenas revela sua dificuldade em separar os manuais dos manuais, típico de quem não consegue identificar a Ciência Normal do Direito, aquela que já não separa os saberes voltados à explicação do fenômeno jurídico, o que não se confunde com manuais de reprodução de texto legislado ou de ementas de julgados.

Kuhn ao tratar do papel do cientista escreve: "durante toda sua curreira $o$ cientista deve se ocupar com operações de limpeza" (Kuhn, 2000, p. 44). Para tanto, o cientista do Direito precisaria se tornar uma profissão, no entanto, se nem professor de Direito é profissão no Brasil. que dizer do cientista? A dificuldade está em, além de ter que lutar para um reconhecimento no âmbito profissional, o cientista do Direito tem que buscar outras fontes de sobrevivência que sua atividade cientifica e, ainda, os manuais reprodutores são mais procurados que manuais científicos. ainda mais depois da multiplicação de cursos de Direito no País. De volta ao tema, recordo Kelsen, um dos autores mais citados e menos lido.

Kelsen, que identifica o Direito com o Estado, ao enfrentar o tema da decisão jurídica escreve "nenhuma ordem jurídica pode prevenir todos os possíveis conflitos de interesses" (1999, p. 270) e explica que a indeterminação não intencional do ato de aplicação do direito se deve à "pluralidade de significações de uma palavra" já que "o sentido verbal da norma não é unívoco, o órgão que tem que aplicar a norma encontra-se perante várias significações possiveis" (1999, p. 389). E?

Antes da resposta um informe. Para Kelsen toda decisão judicial é criação de direito, pois é a passagem do abstrato para o concreto. A decisão judicial é quem efetiva. produz direito entre as partes, individualiza o Direito. Mais, Kelsen reconhece validade à decisão contra-legem:

quando uma norma jurídica individual, a criar pelos tribunais, não istá por forma alguma predeterminada numa norma jurídica geral positiva. essa norma jurídica individual é posta com efícácia retroativa... Isso ocorre quando o tribunal aplica ao caso que tem perante si uma norma juridica individual, somente por ele criada. cujo conteúdo não está predeterminado em qualquer norma jurídica geral positiva, quando essa norma juridica individual liga uma consequêencia do ilícito a uma conduta do demandado ou acusado que, no momento em que teve 
lugar, não era ainda um ato ilícito, mas só foi tornada através dessa norma juridica individual da decisão do juiz (Kelsen. 1999, p. 272).

Como explicar a decisão contra legem em Kelsen? Simples, a ordem jurídica contém normas constitucionais e processuais que validam as decisões transitadas em julgado. Parece aqui faltar critério à decisão judicial, ou ainda, parece que Kelsen defende que não há limite à interpretação. por isso o julgador pode decidir com arbitrariedade. Não é isso. Só leitores limitados a manuais não-científicos poderia chegar a essa conclusão.

Kelsen fala em discricionariedade. A ordem juridica estabelece limites à interpretação, para explicar isso ele recorre à imagem da moldura como limite à interpretação de um quadro. Acontece que há diferentes graus à livre apreciação do julgador (1999, p. 272), portanto a ordem jurídica comporta decisão contra legem e sua validade decorre da aplicação das normas superiores à decisão, base da pirâmide. Por exemplo, a Constituição e a norma processual prescrevem a competência dos tribunais para tornarem um caso concreto juridicamente indiscutível. Numa frase: uma decisão, mesmo contra legem, ao transitar em julgado é aplicação de norma superior, posto não caber mais recurso.

Voltando ao nosso E? Nossas observações se pautam pela idéia de a Ciência do Direito não ter vivido uma revolução cientifica, ou seja, não ter sofrido alteração de paradigma. Já afirmamos que afirmar ser o direito um fenômeno social implica não reduzir o direito ao Fstado, contudo isso não implica rompimento, entre os doutrinadores e na prática forense, de mentalidade.

É que ainda prevalece, no pensar jurídico, o paradigma ontológico. o apego à busca da verdade, como se o conhecimento dependesse da coisa em si. como se a racionalidade fosse pautada pela relação causa e efeito. Predomina, também, na produção doutrinária do Direito uma nítida referência à verdade fática. Abordagens de temas como a teoria do ato jurídico, a teoria da validade, a teoria da prova revelam o quanto o pensar jurídico ainda se pauta pelo paradigma ontológico, como o paradigma da linguagem nunca tivesse atingido "sucesso" nesse ramo do conhecimento. É como se a doutrina do Direito não tivesse passado ao giro hermenêutico. Quem sabe por isso, ainda há quem diga: "Filosofia e Sociolugia do Direito são perfumarias"

Tudo isso evidencia a constatação da não transposição para o paradigma da linguagem na C.iência do Direito. Aumenta a depressão quando se constata que, inclusive os que escrevem com inserção na teoria da linguagem. ainda estão apegados ao debate sobre a teoria do signo voltada à relação sujeito/objeto ou sujeito/sujeito. O que, 
desde 1878, com a publicação do livro How to make our ideas clear, de Charles Sanders Pierce, já nega essa proposta na lingüística.

Significa dizer: enfrentar a decisão jurídica como objeto de pesquisa implica incluir no estudo a comunidade forense, do que resulta a necessidade de se estudar a ordem social forense. Ou ainda. a construção social da realidade jurídicoforense. Daí o título deste texto: ordem social forense e decisão jurídica.

Investigar os mecanismos desenvolvidos pela comunidade que dão continuidade ao convívio social, envolve pesquisar a comunicação entre os integrantes dessa comunidade, o que não significa ignorar pesquisas como as de Cláudio Souto (1986, p. 197-214), Joaquim Falcão (1984, passin) e Eduardo Faria (1989, p. 95-109) entre outros como Machado Neto e Miranda Rosa. Para isso, somar o instrumental teórico da lingüística à teoria social é fundamental. O primeiro nos permite investigar os signos lingüísticos cotidianamente produzidos, propiciando uma explicação da pluralidade de decisões como produto da comunicação entre os juristas; o segundo conduz à identificação de etnométodos que permeiam a ordem social forense.

Pesquisar a comunicação forense partindo da visão de Luhmann e os etnométodos da interação social da comunidade forense está indicado como caminho. método de pesquisa, para se explicar as tomadas de decisão jurídica.

2. Insuficiência da teoria da argumentação para explicar a Decisão Jurídica

Não ignoramos que há cientistas jurídicos voltados à tentativa de produzir alteração no paradigma do Direito, contudo esses esforços têm sido insuficientes para se considerar ter havido mudança na visão de direito predominante na doutrina e na prática forense.

Não se trata de defender que a prática jurídica necessita da explicação do que nela se faz e como nela se vive ou sobrevive. Parece-me, inclusive, que a conscientização do que nela se faz e como nela se vive deve ser prejudicial ao exercício profissional. Não pretendo desenvolver essa questão ética. apenas faço registrar quc, se para o tecnicismo experiencial forense é suficiente repetir modelos de petições e sentenças (Stamford, 2004b, passim), para quem objetiva uma explicação da tomada de decisão jurídica, não há como ignorar que seu objeto de pesquisa não se esgota nesse tecnicismo.

Luiz Alberto Warat, por exemplo, com sua proposta de um programa de semiologia política (1995, p. 99-103) se lançou na tentativa de promover uma revolução científica no Direito. Outros Autores brasileiros que cito como ocupados com a 
mentalidade do paradigma da linguagem são: Miguel Reale ao tratar das fontes e modelos do Direito como novo paradigma hermenêutico (1994); Tercio Sampaio Feraz Jr. com a proposta de, a partir da distinção entre relato e cometimento, analisar a norma jurídica (1997): Lúcio Grassi de Gouveia ao tratar da interpretação criativa e realização do Direito (2000): Eduardo Bittar que analisa o instrumental lingüístico voltado ao Direito (2001); Noel Struchiner com sua análise da textura aberta do Direito (2002); Thomas da Rosa de Bustamante em suas reflexões sobre a argumentação contra legem (2005), além de livros coletânea como Hermenêutica Plural. organizado por Carlos Boucault e José Rodrigo Rodriguez (2002) e Perspectiva atuais da Filosofia do Direito, organizado por Antônio Cavalcanti Maia e outros (2005).

Outra difículdade está quando se identifica que. não bastasse a teoria da linguagem ser pouco explorada entre os juristas, a teoria da argumentação se mostra insuficiente para explicar a tomada de decisão jurídica. A teoria da argumentação está mais ocupada em oferecer um modelo de como os juristas deveriam julgar. que em apresentar uma análise de como os juristas tomam suas decisões. Tanto a justificação da decisão como controle e instrumento impeditivo da decisão arbitrária, como os caminhos trilhados por teóricos como Perelman. Viehweg. Dworkin e Alexy confirmam nossa constatação.

No caso de Perelman, para a proposta de formar uma noção válida de justiça de caráter formal, são estabelecidos seis critérios materiais para configurar os seres numa mesma categoria: a cada um o mesmo; a cada um segundo o atribuído pela lei; a cada um segundo sua categoria; a cada um segundo seus méritos e capacidade; a cada um segundo seu trabalho; a cada um segundo suas necessidades (1996, p. 85-93). Como, para essa categorização, há a influência de juizos de valores, esses autores vão buscar nos raciocínios analíticos e dedutivos a forma como se raciocina a propósito de valores.

Sendo os raciocínios analíticos, lógico-formais, porque das premissas a conclusão é necessária, enquanto nos raciocínios dialéticos, retóricos, das premissas a conclusão é plausível, Perelman localiza o raciocínio jurídico como espécie de raciocínio dialético e, com isso, defendem que, por ser a conclusão plausível, sempre há um auditório a ser persuadido, para o que a argumentação é vista como um tecido e não um encadeamento de idéias, contrariando Descartes (1996, p. 469-557). Na construção tcórica desses Autores, o estudo da argumentação é dividido em três partes: os pressupostos ou limites; os pontos ou teses de partida; e as técnicas argumentativas.

O que nos interessa aqui não é desenvolver a tcoria da argumentação de Perelman e Olbrecht-Tyteca. mas simplesmente demonstrar que ao identificar como 
auditório da argumentação o auditório universal, a construção teórica perde seu contato com o mundo empírico. Ora, sendo o auditório universal um conceito limite, para justificar a afirmativa de "a argumentução ser a norma da argumentação objetiva" um ideal por envolver todos os seres dotados de razão; uma construção do orador e não uma entidade objetiva, ele. o auditório universal, não é um conceito empírico. Há ainda construções de propostas ideais como a de a argumentação, por sua proximidade com a prática, não permitir se falar em objetividade, mas em imparcialidade, considerando-se imparcial a não-antecipação da decisão favorável a uma das partes do processo. Todavia não há uma referência ao mundo empírico das decisões jurídicas, por exemplo, assim como não há quando defende que a argumentação tem estreito contato com a regra de justiça: "atuar do mesmo modo diante de casos análogos" e "os critérios seguidos devem ser válidos para o maio número de destinatários" Ainda mais, ao expor o tema dos pontos de partida. esses autores constroem uma diferenciação entre acordos em auditórios particulares e em auditórios universais típica de teorias moralistas sem contato com a vivência entre seres humanos (1999, p. 34-77).

Como explica Cláudia Monteiro, o contato com os espíritos na teoria da argumentação de Peralman e Olbrecht-Tyteca significa que argumentar envolve a intersubjetividade em pelo menos dois níveis: o da linguagem comum, quando se tratar da comunidade que compartilhe a linguagem, portanto da formação de regras de comunicação que regulam o diálogo em qualquer nível numa sociedade; e da comunidade igualitária, aquele na qual a argumentação não é intimidação pois exclui a violência, a força física e a psíquica (2003, p. 56 e ss).

No caso de Viehweg a argumentação como pensar problemático, no caso de Dworkin o recurso ao juiz ideal Hércules e, finalmente, no caso de Alexy a proposta de juizos de ponderação, não bastam para enfrentar o tema da decisão jurídica, principalmente quanto se problematiza a tomada de decisão jurídica, visando explicá-la partindo da prática forense.

Com isso, apenas nos referimos à necessidade de que a investigação da decisão jurídica requer muito mais métodos de interpretação c țorias da argumentação como marco teórico.

Insisto, inclusive, que o estudo de Kelsen e Hart são suficientes para evidenciar essa afirmação. Ambos identificam questões lingüísticas como a ambigüidade e a vagueza dos termos juridicos, bem como defendem que há limites hermenêuticos e, por isso, falam em discricionariedade e não em arbitrariedade. Esses dois Autores terminam recorrendo à expressão comunidade juridica quando tratam da decisão judicial (Stamford, 2005a, passim). Por que? 
Porque não há como evitar uma ampliação da dimensão teórica, quando se trata de investigar a decisão jurídica; tanto porque o texto da norma não lhe estabelece limites, como se explica nos debates de cunho lingüístico (teoria do signo, teoria do código, teoria da representação; a relação sujeito/objeto ou mesmo sujeito/sujeito), como devido ao debate sociológico.

É que não há como enfrentar o tema da decisão judicial, ignorando por objeto de pesquisa a comunidade forense. Principalmente porque não cabe reduzir a decisão ao magistrado. Advogado, procurador e promotor também tomam decisões ao escolher a via argumentativa numa petição, por exemplo (Stamford, 2000, p. 142-145). Não é tão simples tratar da decisão jurídica. Um advogado, ao elaborar uma petição inicial toma decisões ao escolher os argumentos a contarem na petição, principalmente quando escrevem os pedidos. O mesmo ocorre com os demais juristas: promotores, procuradores e magistrados. Quando dissemos que não cabe recorrer ao discurso da relação sujeito/objeto ou mesmo sujeito/sujeito é que já não cabe explicar a interpretação, recorrendo a idéias como vontade do legislador ou vontade do texto. $\mathrm{O}$ processo comunicativo é bem mais complexo que esses reducionismos.

A garantia que um advogado pode ter de que o juiz vai compreender o conteúdo da petição da maneira como ele. advogado, deseja, não é resultado da intenção do Autor, nem do conteúdo do texto. Não se trata de uma verificação do subjetivismo do Autor, nem da objetividade do texto. A comunicação envolve muito mais fatores que esses. Tão pouco basta enfatizar o contexto, como fazem os pragmáticos.

O processo comunicativo também não resulta de uma relação comunicativa pautada por regras de comunicação como forma de garantir a transmissão da mensagem comunicada; é que o signo não é composto apenas por significante (objeto) e significado (representação) e tem por princípios a arbitrariedade e o caráter linear (Saussure, 2003, p. 79-84), nele há também o intérprete, pois o signo e a explicação formam um outro signo (Pierce, 1999, p. 45-47). A visão tríade do signo proposta por Picrce é suficiente para se identificar o quanto o processo comunicativo é complexo e, portanto, requer uma teoria complexa para explicá-lo.

Para complicar ainda mais. não se trata de estudar a intencionalidade do leitor. do intérprete, por exemplo, do magistrado. Imagine que um promotor, por dividir a vara judicial com o magistrado, conheça as preferências, a visão de mundo do magistrado. Isso não garante que uma petição do promotor, enxertada por signos lingüísticos identificados como previamente ao gosto do magistrado, garanta uma decisão favorável. 


\section{Eterna necessidade de limpeza cientifica}

Partimos da provocação: se a legislação é a mesma por quê há uma pluralidade de decisões? Várias respostas já foram apontadas: entre elas destacamos: porque interpretar é valorar; porque a linguagem é ambigua e vaga, por isso há mais de uma interpretação possível; porque o sistema jurídico sofre interferência dos sistemas econômicos e políticos; por questão cultural, como é o jeitinho brasileiro.

Essas respostas podem confortar o leitor, mas revelam mais opiniões pessoais de autores que produto de pesquisas cientificas. Para manter a afirmação de que o magistrado primeiro decide é recorre ao texto legislativo para legitimar sua decisão não tem respaldo científico. Que pesquisa científica comprova essas hipótese?

Apenas chamo atenção para a necessidade de evitar que a Ciência do Direito se mantenha como produto de opiniões pessoais, ou ainda, espécie de solipcismo.

Falamos em ordem social forense para explicar que a decisão jurídica é resultante da comunidade forense, por isso é indispensável incluir o estudo sociológico para explicar a decisão jurídica.

Niklas Luhmann nos oferece uma teoria semântica voltada à explicação da decisão jurídica; portanto, do sistema jurídico. Não há como tratar do pensamento de Luhmann sem exercer a função de limpeza, como previsto por Thomas Kuhn. É que Luhmann, assim como Kelsen, é um autor bastante citado, mas pouco lido.

Não-só a produção do Autor é extensa como seus comentadores e adversários são muitos, entre eles, não se pode deixar de referir, está Habemas. Sempre que me refiro a Luhmann as primeiras frases que escuto são: é um conservador; só se preocupa em justificar a ordem; exclui o ser humano como integrante da sociedade, defende o assujeitamento; ninguém mais credita no funcionalismo como passível de explicação da vida social: sua teoria é solipcista, desconectada e desconexa com a realidade social.

Tentando limpar idéias apressadas. concepção de ouvir dizer ou, na melhor das hipóteses, leituras apressadas, costumo lembrar que na teoria luhmaniana não se fala em in put, out put e feedback, mas em autopoiese, re-entray e order from noises. É um engano dizer que Luhmann usa termos para dizer a mesma coisa já dita. O fato de Luhmann explorar elementos da teoria dos sistemas de Talcott Parsons não significa que se limita a Parsons, o que há é um desmonte das categorias parsonianas, via a biologia cognitiva de Maturana e Varela, quando utiliza termos como autopoiesc, autoreferência, acoplamento estrutural, diferenciação e evolução; da cibernética com Ashby, recorrendo a termos como complexidade (lei de variedade de requisitos); da matemática com 
George Spencer Brown e Heinz von Foerster. explorando idéias como a circularidade, observador de segunda ordem e re-entray; da fenomenologia de Alfred Schutz, explorando a concepção de senso e mundo; ou dos saltos entre sistemas como em Douglas Hofstadter (2001, passin).

Só para evidenciar o quanto L.uhmann constrói uma explicação sociológica própria, vejamos a noção de forma de George Spencer Brown. Para este Autor, forma é simultaneamente observação e observado, além de ser ato criativo intrínseco ao fazer uma observação, o que remonta a Charles Peirce e seus escritos, de 1890. Com isso apenas queremos demonstrar que Luhmann identifica na teoria dos sistemas elementos capazes de oferecer uma explicação sociológica da vida em sociedade: todavia, adiciona elementos partindo da teoria da linguagem, principalmente porque, para Luhmann. comunicação é uma operação específica dos sistemas sociais. Uma vez explicado o processo comunicativo, é possivel entender os processos decisórios. Fssa é a proposta luhmanniana. Não cabe, no entanto, confundir comunicação com emissão de informação. Perceber que alguém disse algo não implica comunicação, esta torna a informação uma seleção. pois provoca uma distinção no mundo entre aquilo que é dito e aquilo que é excluído diante do dito. Enfim, comunicação é uma operação específica que identifica os sistemas sociais. Através da comunicação os sistemas estão abertos ao ambiente, pois o ambiente vem construído comunicativamente na informação (Luhmann, 1983, passin; Luhmann, 1985, p. 3-5; Luhmann, 1998, pp. 108-110; 140-170; Luhmann, 2000, p. 4-6; 136-146; Luhmann, 2001, passin; Luhmann, 2003, 20 ss.). Antes desse tema, um parênteses.

Ainda sobre a teoria dos sistemas, se aqui coubusse defender Parsons, explorariamos a análise de Jeffrey Alexander e sua perspectiva neofuncionalista, para quem não há como acusar Parsons de defensor da ordem, da estabilidade, por ignorar o conflito. As críticas sofridas por Parsons pela teoria do conflito e pela teoria do intercâmbio são de ordem ideológica e não-teórica, segundo Alexander. É que a década de 50 produz um clima de violência, devido a movimentos sociais como as lutas de classes e as raciais, gerando uma atmosfera pessimista e crítica. Do ponto de vista teórico, Parsons foi um marco da sociologia, não por isso a pretensão de produzir uma teoria sólida do sistema social resultou no uso de termos ambíguos e confusos. Mas isso não justifica atribuir a Parsons um estruturalismo radical e desconhecedor do conflito social como integrante do sistema social. A questão é que Parsons ao tentar combinar o individualismo com a igualdade pretendia explicar tanto a instabilidade social quanto processo de alcance do consenso político e do equilibrio social, o que o levou a considerar a dinâmica e a interpenetração dos subsistemas. No esquema AGIL - 
Adaptação (dinheiro), Goal Ability (capacidade para alcançar metas política), Integração (normas) e padronização (valores), cada um dos subsistemas do sistema social se cumunicam e sofrem mudanças no processo de adaptação (Alexander, 2000). Voltemos a Luhmann.

A comunicação se dá na forma de decisão. É que ela, a comunicação, é uma operação específica dos sistemas sociais. produto de três seleções: a emissão ou ato de comunicar; a informação e a compreensão da diferença entre emissão e informação. Há comunicação se Alter compreende que Ego emitiu uma informação, caso Alter não perceba que Eco emitiu uma informação, não há comunicação, pois a compreensão realiza a distinção que funda a comunicação entre emissão e informação (1983. p. 294298).

O esquema de Luhmann é:

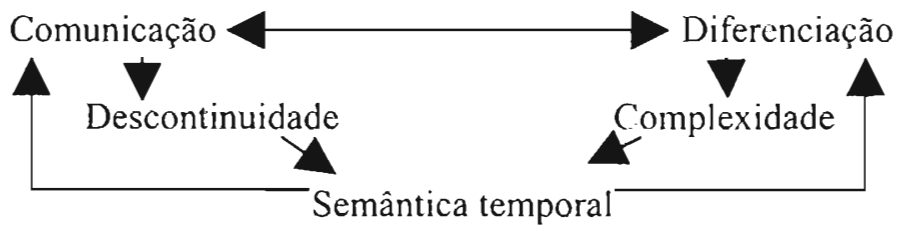

Comunicar envolve, portanto. decidir e diferenciar, pois Ego escolhe o que e como emitir a informação, ao mesmo tempo que envolve a compreensão de Alter. Dizer que a comunicação é um processo sistêmico. significa defender que a vida em sociedade produz uma seleção dentre a possibilidade para fazer existir sentido ao que se quer comunicar. Significa, ainda, considerar que há uma relação entre a estrutura social e a tradição semântica. É que Luhmann parte do pressuposto que "lodas as vivências $e$ as ações humanas se desenvolvem conforme o sentido e são em si mesmos acessíveis só em conformidade como sentido" (1983, p. 15). Trata-se da metodologia circular. Cada sistema social é uma diferenciação sistêmica que o diferencia dos outros sistemas sociais, essa diferenciação sistèmica não tem referência ao ambiente ao mesmo tempo que tem referência ao ambiente para promover a diferenciação sistêmica que o produz como sistema semanticamente diferenciado. Essa aparente confusão de o sistema se referir e não se referir ao ambiente é a autopoiese. Se para a Biologia de Maturana autopoiese é a explicação de que cada célula é produto de um retículo de operação. na teoria social de Luhmann este conceito é ampliado pois além de se referir ao fechamento operacional. que permite a construção de identidade sistêmica, bem como ao acoplamento estrutural. que é a constante influência do ambiente, envolve a autoreferência, capacidade de operar diferenciação partindo de seu interior. Outro engano é 
atribuir a Luhmann uma redução de tudo a sistemas autopoiético. Apenas este autor defende que só há sistema se houver autopoiese, mas não por isso tudo na vida social é sistema.

Sobre a mudança social. A visão de evolução, partindo da Biologia, explica que a evolução de uma espécie pode significar a sua extinção. Luhmann, sobre o tema, elabora as seguintes espécies de diferenciações para demonstrar a evolução social: a diferenciação segmentária tem lugar quando cada sistema vê o ambiente interno da sociedade como acumulação de sistemas iguais ou similares, isso ocorria nas sociedades não-complexas; a diferenciação estratificada ocorreu quando cada sistema tratava o ambiente interno da sociedade como externo e os demais sistemas como desiguais; por isso, havia a necessidade de se definir uma hierarquização entre os sistemas sociais, como ocorrem nas sociedades complexas: a diferenciação funcional aparece nas sociedades hipercomplexas, nas quais cada sistema social vê o ambiente interno da sociedade e os demais sistemas como articulações e partes integrantes de si mesmo (1983, p. 22-25). Mais uma vez, a comunicação permite a evolução, porque a linguagem não põe limites à variedade de comunicações e sim a vida social é que produz a diferenciação. A questão é que há mecanismos de variação, de seleção e de estabilização em cada sistema auto-poiético; todavia, não há automatismo nem hierarquia entre esses mecanismos. A comunicação. inclusive. contribui para provocar "irritações" estruturais no sistema. porém a ocorrência dessa contribuição é imprevisível.

Articulando a teoria da complexidade, com a teoria dos sistemas autopoiéticos e a teoria da diferenciação funcional, Luhmann explica que toda comunicação envolve uma diferenciação, cada palavra utilizada implica no afastamento do uso de outras palavras, assim a formação do sentido (senso social) implica num recurso a estruturas de linguagem antecedentes simultaneamente à produção de transformações dos conceitos; por isso, os limites imaginados à comunicação não passam de necessidade operativa, jamais resultando na formação de conteúdos últimos aos termos empregados. Por isso o consenso sobre aquilo que $\mathfrak{e}$ ou aquilo que vale é visto como difícil e autenticamente impossível. O senso, portanto, é contingente e temporalmente limitado. $\dot{E}$ dessa hipótese que Luhmann constrói a conexão entre estrutura social e tradição semântica. Para isso, o Autor nos oferece o seguinte esquema (1983, p. 32): 


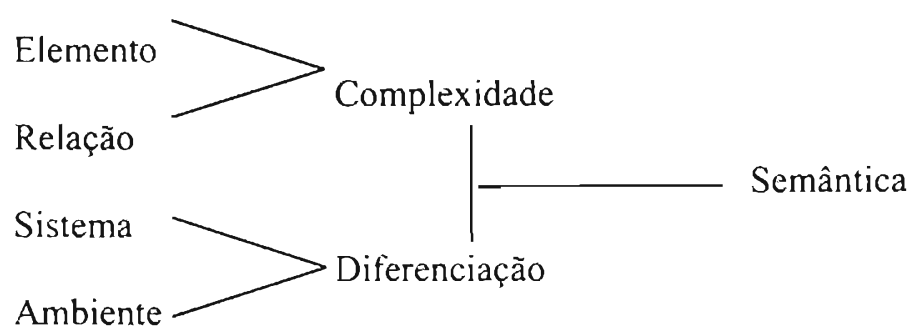

Desse esquema se deduz que a forma de diferenciação produz correlatos semânticos mediados pela situação da complexidade do sistema social. É que assim como a teoria da complexidade não produz previsões quanto à conexão entre elementos e relações, a teoria da diferenciação não produz previsões quanto à conexão entre o sistema e o ambiente. Portanto, "se se supõe que as mudanças da forma de diferenciação e os acréscimos da complexidade social mudam o mundo de senso no qual os seres humanos vivem, se pode chegar só se decompondo o conceito de senso" E é senso que mantém acessivel todo o mundo, justamente por permitir a contínua seleção ao próximo passo num contexto mais ou menos concretamente percebido de outra possibilidade. Trata-se da semântica do sistema social, pois no mundo da vida promovemos formas gerais de ordem de seleções. Essa seletividade é que permite a variação das articulações do mundo, como se faz na semântica fundamental para percepção do mundo.

$\mathrm{O}$ até aqui exposto é suficiente para nos permitir afirmar a semântica luhmanniana como marco teórico a uma pesquisa sobre a decisão juridica, principalmente se o objetivo é identificar mecanismos produzidos no cotidiano forense da comunidade juridica. Inclusive porque a concepção luhmanniana de semântica do sistema social permite tomar consciência da imprevisibilidade. devido à evolução. pois esta. a evolução, é a garantia de continuidade. Assim como ocorre com uma teoria da evolução social. ocorre com a história etimológica e conceitual (Luhmann, 1983. p. 3233; Neves. 2001, p. 127).

Para melhor basear nossa proposta metodológica, recorremos. sem abandonar Luhmann. à etnometodologia, como forma de identificar mecanismos socialmente desenvolvidos na produção da decisão jurídica.

\section{Etnométodo}

A etnometodologia. fundada por Harold Garfinkel, ganhou atenção principalmente após seu artigo de 1963: "a conception of and experiments with 'trust' as a condition of concerted stable actions" e com seu livro, de 1967. Studies in 
ethnometodology. O Autor explica que usa o termo Etnometodologia para se referir à "investigação das propriedades racionais das expressões indexadas e outras ações práticas como realizações contínuas e contingentes de práticas usadas como artificios para organizar a vida cotidiana" (1996, p. 11).

A partir das palavras etnobotânica, etnofisiologia, etnofísica, Harold Garfinkel chegou ao termo etnometodologia para se referir à capacidade do ser humano dotar, de sentido, seu mundo social, assim: etno se refere aos "sistemas conceituais cotidianos empregados pelos membros de uma cultura ou de uma sociedade dada"; metodologia são "os procedimentos implementados pelo senso comum na representação corrente do mundo e da ação"(Amaud, 1999, p. 333; Wallace e Wolf, 994, p. 320).

Estudou com Talcott Parsons e Alfred Schutz. Via Parsons fundamenta se nas idéias coletivistas de Durkheim e Weber, via Schutz, na visão individualista da fenomenologia de Edmund Husserl. Garfinkel se propõe a unir essas explicações da vida social (Alexander. 1987, p. 205, 208-225; Ritzer, 1993, p. 287-291). Daí que: seguindo Parsons, Garfinkel, explica que as normas estão internalizadas, porém, seguindo Schutz, elas são elaboradas. Dessa forma o Autor retorna à proposta de fato objetivo de Durkheim, porém agora passível de modelagem pelos atores. Significa que os dois paradigmas sociológicos da época (o da normatividade e o interpretativo) se associam na etnometodologia, porque a significação dependente dos atores. A comunicação não é fruto de referência ao inundo exterior, sua referência simbólica, nem de aplicação de normas fixas de significação e sim da interpretação que cada ator adota, mais, não-só do dito, mas também de gestos, olhares e sons emitidos durante a comunicação. Para defender essa idéia Garfinkel diz que criamos etnométodos para viver em sociedade, refere-se aos procedimentos e considerações que utilizamos para dar sentido às circunstâncias em que nos encontramos.

Um dos artifícios de Garlinkel foi recorrer aos "experimentos de ruptura" Fle pediu a um grupo de alunos que passasse a se comportar em casa, no ambiente familiar, como se fossem visitas. Isso obrigaria a uma quebra do padrão esperado de comportamento dos alunos entre seus familiares. Ao relatarem a experiência foram registrados várias situações de desentendimento na família. Além desse, outros métodos de verificação dos etnométodos foram criados como a análise de conversação (que não se confunde com análise de discurso), provocações de aplauso, integração do discurso e das atividades não-verbais.

Etnometodologia, portanto, não é um método de pesquisa nem uma técnica de levantamento de dados, é um programa para investigar acordo entre colegas culturais, ou ainda: "Fu uso o termo ethnomethodology para me referir à investigação 
das propriedades racionais de expressões de indexação e outras ações de práticas contínuas e contingentes organizadas na vida cotidiana" (Garfinkel, 1996, p. 10-11).

Confirma-se, assim, que não se trata de um método de investigação, nem de uma técnica de pesquisa e, sim, de um programa de pesquisa voltado ao estudo do "aspecto processual e implícito do conhecimento que os agentes utilizam nas atividades rotineiras" (Arnaud, 1999, p. 332), ou seja, de como as pessoas tornam compreensiveis as cenas e situações sociais (Wallace e Wolf. 1994, p. 321).

\section{Teoria Social e Etnometodologia}

Criticando a construção das teorias sociológicas, a etnometodologia se contrapõe ao positivismo sociológico, em suas vertentes estruturalismo e funcionalismo, principalmente por eles promoverem uma realidade social diversa da real ao criarem tipos sociais ideais como forma de possibilitar a análise e explicação da vida em sociedade. A etnometodologia rejeita essa construção teórica, bem como não aceita a idéia de o fato social ser considerado como algo dado, conforme defende a teoria da atribuição de rótulos (labeling theory) (Coulon, 1995, p. 16); para ela, a etnometodologia, o convivio social produz e constrói uma percepção de vida, uma visão de fatos sociais, assim ela rejeita os que consideram o ator social um "imbecil desprovido de juizo"(Wallace e Wolf, 1994, p. 228).

Assim, no programa etnometológico, os métodos e técnicas de pesquisa são definidos segundo o objeto de investigação. Quanto às técnicas de investigação empírica, os etnometodólogos recorrem à técnica da pesquisa documental, da observação, da gravação de fitas de áudio e de vídeo, tudo voltado à abordagem de como as pessoas constroem e reconstroem a realidade social em que vivem.'

Como acima afirmado, tendo sido orientado no doutorado por Talcott Parsons. no período de, 1946 a 1952, e estudado a perspectiva fenomenólogica de Edmund Husserl, Aaron Gurwitsch, Alfred Schütz e Maurice Merleau-Ponty, Garfinkel sofre nítida influência desses autores (Coulon, 1995, p. 19). Passemos então por esses Autores para compreender melhor a proposta de investigação da etnometodologia.

Edmund Husserl. considerado primeiro Autor a utilizar o termo fenomenologia, empregou-o para tratar da dualidade da consciência, daí o autor distinguir psicologia pura mundo da consciência do mundo dos modos de conhecer. $\dot{\mathrm{E}}$ que o descobrimento psicológico do me mesmo é objeto de estudo da psicologia pura

Este texto não se ocupa das técnicas de pesquisa, para quem se interessa, não só pela técnica, mas com a análise de dados obtidos através de textos, imagens e som, ver: BAUER, Martin W.; GASKELL. George. Perquisa qualitativa com texto, imagem e som. Petropolis: Vozes, 2004. 
preocupada com a realidade psicofísica (animal); já a fenomenologia estuda as variantes fenomênicas da consciência. O que tem estreita ligação com a separação que Luhmann faz entre sistema social e sistema psíquico $(1985$, p. 9 ; 81; 117). É a distinção entre a perspectiva do ego cogito e a perspectiva da descrição concreta da consciência. Daí que a fenomenologia abre a possibilidade de estudo de fatos jamais investigados antes dela, porque trata da investigação dos fatos da estrutura sintética que dão unidade noéticonoemática às distintas cogitações (Husserl, 1996, p. 87).

Da proposta de estudo dos atos mediante os quais a consciência se reporta à realidade ou ao seu significado, Husserl realiza uma mudança de atitude na teoria do conhecimento: o investigador deve procurar afastar-se do que é tido por aspecto ôntico, apodítico, como a idéia de atitude natural do ser humano, pois a atenção do pesquisador se desloca do mundo mesmo (da sua realidade) para os fenômenos com os quais esse mundo se anuncia e se apresenta na consciência, isto é, na consciência mesma e nas suas estruturas essenciais (Husserl, 1996, p. 62-63). Neste sentido a consciência constitui o residuo fenomenológico (Abbagnano, 1993, p. 429-430).

Assim pensando, Husserl aponta duas condições fundamentais para a fenomenologia: a redução eidética, substituição da consideração dos fatos como naturais por intuição da essência dos fatos; e a epoché fenomenologica, que é o suspender a tese da existência do mundo (Husserl, 1996, p. 122-123).

O conhecimento, em Husserl, portanto, envolve o estudo da intencionalidade (Husserl, 1996, p. 89). Admitindo a distinção sujeito/objeto, o Autor distingue o aspecto subjetivo e objetivo do conhecer um objeto. Nossos atos de observação e apreensão do objeto é o aspecto subjetivo, chamado de noesis; o aspecto objetivo não é o objeto mesmo (a "coisa em si" de Kant), mas o que, devido à experiência vivida, nos leva a ter determinada percepção do objeto, qualificando-o, que é o noema.

Dessa forma, quando um objeto é percebido e rapidamente se enquadra nos modelos de nossa experiência vivida, a intuição, a evidência e a verdade podem coincidir; o que possibilita a racionalidade. Algo é racional quando coincide com a evidência, ou seja, quando lhe damos o atributo de estar de acordo com nossa intuição, com os limites dados por nossa experiência. Daí sempre haver a intencionalidade no ato de conhecimento, que é a intencionalidade da consciência (Husserl, 1996, p. 95-99).

Husserl, ao abordar o tema da relação entre teoria e prática (objetividade e subjetividade), fala em mundo cultural (mundo da vida) que é aquele onde as pessoas vivem intuitivamente e em consciência objetiva do mundo, o qual é acessivel a todos (Husserl, 1996, p. 199). 
Da idéia de mundo da vida de Husserl, Alfred Schutz trata o mundo social como o mundo da vida (lebenswelt), ${ }^{3}$ um mundo intersubjetivo, o mundo das rotinas, sendo a realidade social "a soma total dos objetos e dos acontecimentos do mundo cultural e social, vivido pelo pensamento de senso comum de homens que vivem juntos numerosas relações de interação" (Coulon, 1995, p. 12).

Dessa localização, Schutz se preocupa em distinguir o mundo da vida do mundo dos sonhos, para isso identifica seis características do mundo da vida: o estado de alerta, momento em que o ator presta atenção à vida e aos seus requisitos, o que não ocorre no mundo dos sonhos; segunda, o fato de o ator não duvidar da existência do mundo; terceira, refere-se ao mundo do trabalho, que está ausente no sonho; quarta, a forma específica do trabalhador experimentar o mundo; quinta, é quando o mundo da vida é caracterizado pela solidariedade; e sexta, o fluxo temporal, o qual é diverso entre o mundo da vida e o mundo dos sonhos (Ritzer, 1993, p. 272).

Assim, quanto aos reinos da realidade social, esse Autor distingue quatro espécies: umwelt (reino da realidade social diretamente experimentada, que é o contato face-a-face, são as relações-nós (eu e tu)); mitwelt (reino da realidade social indiretamente experimentada, contatos intermediados por instituições e organizações sociais, formando as relações-eles) folgewelt (reino dos sucessores, quando debate sobre a previsibilidade da ciência social) e vorwelt (reino dos predecessores. capacidade de analisar o ocorrido a partir do instrumental teórico oferecido pelas ciências sociais) (Ritzer, 1993, p. 274-279).

Sendo Schutz um precursor de Garfinkel, acrecentamos ainda a informação que do conceito de verstehen (compreensão) de Max Weber, ele elabora um estudo sobre o significado que os indivíduos atribuem às situações que presenciam. Isso o permite defender que a convivência entre os seres humanos resulta justamente do fato de que, como cada ser humano vive experiências diferentes das dos outros, criamos o mecanismo de supor que tivemos experiências idênticas. Assim. vivemos um processo de permanente ajuste. o qual torna possivel a dissipação das divergências entre as diferentes percepções de mundo (Coulon, 1995, p. 10-12). Aproveitando essa informação, este processo foi chamado por Mead de "fundo comum de consciência" o qual permite-nos pensar o mundo em termos de "tipos" de objetos, que é o processo de elaboração das tipologias (ou idealtipos) (Wallace e Wolf, 1994, p. 317).

Schutz utiliza vários termos como sinônimo de mundo da vida, tais como: "mundo da vida diária". "mundo do trabalho cotidiano". "realidade mundana", "mundo do sentido comum". "realidade eminenti da vida do sentido comum" (RITZER, G. Teoria sociológica contemporinea. Madrid: Mcliraw-Hill, I 993. p. 270). 
Harold Garfinkel, partindo do conceito de "expectativa normativa" de Parsons, oferece a proposta de um estudo do comportamento cotidiano, contrapondo-se à idéia de padrão de comportamento nos termos empregados pelo estruturalismo e pelo funcionalismo. assim a etnometodologia considera que a ordem é construída dentro dos processos sociais, resultando das relações sociais compartidas. Com Schutz, Garfinkel defende a necessidade de um motivo particular para por em questão o mundo comumente conhecido e dado por sabido (Wallace e Wolf, 1994, p. 332).

Aaron Cicourel, discipulo de Garfinkel, trabalha o tema da metodologia com críticas aos métodos empregados pelos sociólogos em seus experimentos, para este Autor os sociólogos afastam elementos indispensáveis à investigação por capricho metodológico. Estas idéias deram margem ao aparecimento de novos métodos como a "etnografia constitutiva" de Hugh Mehan, e o tracking, de Don Zimmerman (Coulon, 1995, p. 85-92).

Ainda sobre a etnometodologia e a metodologia, não se pode deixar de fazer referência a Peter Berger e Thomas Luckmann em seus estudos sobre a construção de um mundo objetivo, a partir dos processos subjetivos, o que, para esses Autores, fundamenta a construção social da realidade (Ritzer, 1993, p. 282-287; Wallace e Wolf, 1994, p. 337-343).

Da vida cotidiana, aquela que se apresenta como realidade interpretada pelos seres humanos, forma-se um significado subjetivo construindo-se o mundo coerente, é que a realidade da vida cotidiana é "o mundo intersubjetivo que comparto com os outros" (Berger e Luckmann, 1983, p. 40). Para esses Autores, pode-se duvidar da realidade cotidiana, porém, mesmo assim, estamos obrigados a suspender essas dúvidas porque existimos rotineiramente, em vida cotidiana. A vida é: rotineira - as que scguem sendo apreendidas como não-problemáticas … ou não-rotineira - aquela apreendida problematicamente.

Estruturalmente, a vida cotidiana tem limites de espaço e tempo. Quanto à limitação espacial, ela, a vida cotidiana, requer uma dimensão social, delimitada conforme o grupo social. Em razão do tempo, ela é cocrcitiva, não se intervém voluntariamente, p. ex., há a norma do quando falar e quando calar, há a delimitação temporal oficial, demarcada pelos aparelhos de relógio (Berger e Luckmann, 1983, p. 44-46). É o que se verifica quando as audiências preliminares, o objeto desta pesquisa, têm que ter duração limitada, não se pode ficar debatendo "o dia todo"

A interação social na vida cotidiana é aquela que temos com os outros em situação face-a-face, a qual permite que, na realidade da vida cotidiana, construamos esquemas tipificadores, permitindo-se a formulação de critérios à qualificação. Há, no 
entanto, uma negociação contínua entre os esquemas tipificadores das partes em interação, o meu esquema com o do outro (Berger e Luckmann. 1983, p. 49). A linguagem (a corporal - como o aspecto facial - ; a de objetos - que proclamam intenções subjetivas do meu semelhante, como a arma -; a dos signos - permitindo a produção de informações de uma intenção, como o SOS -; e a fala expressão oral). é outra forma de coerção da vida cotidiana, pois estamos limitados a seus efeitos, ela nos obriga a adaptarmos a suas pautas. Assim, a vida cotidiana nos conduz à institucionalização, a nos habituarmos, pois "todos os atos que se repetem com freqüência, crea uma pauta que logo pode reproduzir-se com economia de esforços e que ipso facto é apreendida como pauta por quem a executa" (Berger e Luckmann, 1983, p. 57). Noutras palavras. a habitualidade antecede o processo de institucionalização, o qual implica historicidade e controle, pois é uma tipificação recíproca de ações habituais a certo tipo de atores.

Nem por isso deixa de ocorrer mudanças sociais; é que a realidade social é um processo que contém: externalização - atuar humano -; objetivação - processo humano que objetiva o que é externalizado -; e internalização - processo de volta do mundo social objetivado na consciência durante a socialização. Assim, a sociedade é um produto humano c o ser humano um produto social (Berger e Luckmann, 1983, p. 8384).

Neste sentido, identificamos na perspectiva da etnometodologia um lugar teórico capaz. de auxiliar na análise da vida cotidiana forense.

São Paulo, agosto de 2006.

Referências

ALEXANDER. J. Las teorias sociologias desde la segunda guerra mundial. Madrid: Gidisa, 1990.

ARNAUD. A.; DULCE, M. J. Farinas. Introdução à análise sociológica dos sistemas juridicos. Rio de Janeiro/São Paulo: Renovar. 2000.

BERGFR, P. L.; LUCKMANN, T. La Construcción Social de la Realidad. Buenos Aires: Amorrotu, 1983.

ROUCAULT, C. E.: RODRigUES, J. R. Hermcnêutica plural. São Paulo: Martins Fontes, 2005.

BUSTAMANTE, T. R. Argumentação contra legem. A teoria do discurso e a justificação juridica nos casos mais difíceis. Rio de Janeiro/São Paulo/Recife: Renovar. 2005. 
COULON, A. Elnometodologia. Petrópolis: Vozes, 1995.

FALCÃO, J. Os Advogados, ensino juridico e mercado de trabalho. Recife: Massangana, 1984.

FARLA, J. E. Ordem legal X justiça social: a crise do Judiciário e a formação do magistrado. In: DIREITO e justiça, a função social do judiciário. São Paulo: Ática, 1989. p. 95-110.

FERRAZ JR., T. S. Teoria da norma jurídica. Rio de Janeiro: Forense. 1997.

FERREIRA. M. A. A. Em defusa da tentativa de conciliação. In: ESTLDOS juridicos em homenagem a Vicente Ráo. São Paulo: Resenha Universitária, 1973. p. 323-343.

FREIRE. J. P. P. O juiz como consciência social. Porto Alegre: AJURIS, 1980.

GARFINKEL, H. Studies in ethnometodology. Cambridge/Oxford: Polity Press, 1996.

GOUVEIA, L. G. Interpretação criativa e realização do direito. Recife: Bargaço, 2000.

HUSSERL. E. Meditaciones cartesianas. México: Fondo de Cultura Econômica, 1996.

KELSEN, H. Teoria Pura do Direito. São Paulo: Martins Fontes, 1999.

LUHMANN, N. A improbabilidade da comunicação. Lisboa: Veja-Passagens, 2001. Come è possibile l’ordine sociale. Roma-Bari: Laterza, 1985.

.. El derecho de la sociedad. México: Universidad Iberoamericana. 2003.

La realidad de los médios de masas. Barcelona: Anthropos / México: Universidad lberoamericana, 2000.

Sistemas sociales. Lineamentos para uma teoria general. Barcelona: Anthropos / México: Universidad Iberoamericana / Bogotá: CEJA, 1998.

. Struttura della società e semântica. Roma-Bari: Laterza, 1983.

MAIA, A. et al. Perspectivas atuais da filosofia do direito. Rio de Janeiro: Lúmen Júris. 2005.

MONTEIRO, Cláudia. Teoria da argumentação jurídica e a nova retórica. Rio de Janeiro: Lúmen Júris, 2003.

NEVES, Marcelo. Do consenso ao dissenso: o Estado democrático de direito a partir e além de Habermas. In: DEMOCRACIA hoje: novos desafios para a tioria democrática contemporânea. Brasília: UnB, 2001. p. 111-164.

PARSONS. Talcott. La struttura dll 'azione sociale. Bologna: Il Mulino. 1987. 
PERELMAN, Chaïm; OLBERCHTS-TUTECA, Lucie. Tratado da argumentução. A nova retórica. São Paulo: Martins Fontes, 1999.

Ética e direito. São Paulo: Martins Fontes. 1996.

PIERCE, C. Semiótica. São Paulo: Perspectiva, 1999.

REALE, M. Fontes e modelos do direito. Para um novo paradigma hermenêutico. São Paulo: Saraiva, 1994.

RITZER, G. Teoria sociológica contemporánea. Madrid: McGraw-Hill, 1993.

SANTOS, B. A sociologia dos tribunais e a democratização da justiça. Pela mão de Alice: o social e o político na pós-modernidade. São Paulo: Cortês, 1997. p. 161-186.

SAUSSURE, F. Curso de lingüistica geral. São Paulo: Cultrix, 2003.

SOUTO, C. Educação juridica e conservadorismo acadêmico. Desordem e progresso. Porto Alegre: SAFE, 1986. p. 197-214.

STAMFORD, A. Conciliação judicial e ação comunicativa: acordo judicial como negociação versus consenso. Anuário da Pós-Graduação em Direito da UFPE. Recife, n. 13, p. 75-109, 2003.

Etnométodos da comunidade jurídica. Uma proposta de pesquisa sócio-jurídica. Anuário da Pós-Graduação em Direito da UFPE, Recife, n. 15, p. 75-109, 2006 (no prelo).

- Tecnicismo experiencial forense, o saber acadêmico e o saber científico no Direito. A pesquisa como habilidade profissional. Anuário da Pós-Graduação em Direito da UFPE, Recife, n. 14, 2004/2005 (no prelo).

STAMFORD, A.; MELO, M.O.L.: BARBOSA, R.B. Construção judicial do direito. Desde Kelsen e Hart. Ainda somos os mesmos... e vivemos. Revista de informação legislativa, Brasília, a. 42, n. 165. p. 205-218. jan./mar. 2005.

STRUCHINER, N. Direito é linguagem. Uma análise da textura aberta da linguagem e sua aplicação ao direito. Rio de Janeiro/São Paulo/Recife: Renovar, 2002.

WALLACE, R. A.; WOLF, A. La teoria sociológica contemporanea. Bologna: il Mulino, 1994.

WARAT, Luiz Alberto. O direito e sua linguagem. Porto Alegre: SAFE, 1995. 